Medievalia 24 (202I), 5I-67 - ISSN: 20I4-84IO (digital)

DOI: https://doi.org/I0.5565/rev/medievalia. 546

\title{
LA BATALLA DE RONCESVALLES
}

EN LA ANACEPHALEOSIS DE ALFONSO DE CARTAGENA.

TÉCNICAS NARRATOLÓGICAS

EN LAS GLOSAS LATINAS Y CASTELLANAS*

\author{
THE BATTLE OF RONCESVALLES \\ IN ALFONSO DE CARTAGENA'S ANACEPHALEOSIS. \\ NARRATOLOGICAL TECHNIQUES \\ ON THE LATIN AND CASTILIAN GLOSSES
}

\author{
Pablo Rodríguez López \\ IEMYRhd - Universidad de Salamanca \\ prodriguezl@usal.es \\ https://orcid.org/o000-0002-5825-I289
}

Recepción: I4/05/202I - Aceptación: I2/06/202I

\section{Resumen}

La Anacephaleosis o Genealogía de los Reyes de España es la última obra de renombre publicada por Alfonso de Cartagena (ca. 1385 - I456) antes de su fallecimiento. Su rica tradición textual se muestra en que tanto la obra latina original como su traducción castellana han sido glosadas. Este trabajo pretende analizar, tomando como punto de referencia el episodio de la batalla de Roncesvalles en el capítulo dedicado al rey Alfonso II, la técnica mediante la que el glosador - $\mathrm{O}$ glosadores - estructuraba las adiciones de la obra. Se ha seleccionado este punto concreto por la singularidad que supone la presentación y contraposición de las distintas fuentes historiográficas, en algún punto contradictorias, y el modo de lidiar con opiniones contradictorias de autoridades eclesiásticas.

* Este trabajo se inscribe en el proyecto de investigación «Alfonso de Cartagena. Obras completas» FFI 2014-55902-P y FFI 2017-84858-P (Ministerio de Economía, Industria y Competitividad. Ministerio de Ciencia, Innovación y Universidades. Gobierno de España). 


\title{
Palabras clave
}

Bernardo del Carpio, Roncesvalles, relato, narratología, fuentes de autoridad

\begin{abstract}
The Anacephaleosis or Genealogía de los Reyes de España was the last renowned work published by Alfonso de Cartagena ( $c a$. 1385 - I456) before his demise. Its rich textual tradition can be seen in the fact that both the original latin Anacephaleosis, and also its castilian translation have been glossed. The objective of this work is to analyse, by having as reference point the episode of the battle of Roncesvalles in the chapter corresponding the King Alfonso II, the techinque used by the commentator - maybe more than one - to structure the Anacephaleosis's glosses. This chapter has been chosen because of its singularity in terms of presentation and confrontation of the different historiographical sources, at some point contradictory among themselves, and how the commentator sorted out this opposite thesis by ecclesiastical sources of authority.
\end{abstract}

\section{Keywords}

Bernardo del Carpio, Roncesvalles, story, narratology, sources of authority.

A mi abuela Geli

Desde entonces suenan los valles, $y$ dicen los montañeses...

No existe, entre las batallas que tuvieron lugar en suelo hispánico durante los siglos en los que transcurrió la Reconquista, una contienda tan icónica como la que tuvo lugar en Roncesvalles a finales del siglo viIr. De ella, únicamente se tiene por cierto lo siguiente: que tuvo como protagonista a Carlomagno; que este fue derrotado, al menos en primera instancia; y que quizá consiguió una victoria pírrica al final con la pérdida, eso sí, de sus mejores capitanes, el nombre de uno de los cuales da título a la narración más célebre de los hechos de armas que tuvieron lugar en Roncesvalles: la Chanson de Roland.

Sin embargo, las circunstancias que rodearon a esas escasas certezas varían en gran medida en las obras que se hacen eco de la batalla. Desde la gesta rolandiana, en la que el emperador derrotó a los sarracenos que trataron de diezmar la reta- 
guardia de su ejército en el regreso a Francia, hasta la Historia de Rebus Hispanice del arzobispo Rodrigo Jiménez de Rada (ca. II70 - I247), donde los franceses son derrotados por el rey Alfonso II el Casto y el héroe Bernardo del Carpio, el modo en el que se ha abordado la exposición de los hechos ha sido inestable, contradictorio y, en ocasiones, enigmático.

A este respecto, la Anacephaleosis de Alfonso de Cartagena (ca. I385 - I456) resulta paradigmática debido a la aproximación que realiza a dichos acontecimientos en el capítulo dedicado a Alfonso II que, en su tradición textual, presenta un doble relato de la batalla de Roncesvalles. La diferencia clave entre ambas narraciones reside en la presencia - y ausencia - de Bernardo del Carpio como alférez del rey casto en el combate. Los testimonios que incluyen al héroe leonés se caracterizan a su vez por contener unas glosas que no solamente amplían la información, sino que realizan un recorrido a través de las crónicas que durante la Historia se han acercado a la batalla y observa la forma en la que lo han hecho.

En este artículo se analizará el doble relato del capítulo de Alfonso II de la Anacephaleosis con lo que supone para la construcción del mismo la inclusión de Bernardo del Carpio. Además, se prestará especial atención a las adiciones latinas, así como a las contenidas en la traducción castellana, con el objetivo de reflexionar acerca de la técnica del glosador a la hora de contraponer las versiones transmitidas en las distintas crónicas que toma como modelos.

\section{LA VARIACIÓN DEL RELATO DE LA ANACEPHALEOSIS}

La Anacephaleosis de Alfonso de Cartagena ha tenido, desde su conclusión, el 28 de febrero de 1456, una rica tradición textual. ${ }^{\mathrm{I}}$ La proliferación de testimonios latinos y traducciones castellanas — aquella a cargo de Juan de Villafuerte ( $c a$. I44O-I5I4) representa el conjunto de manuscritos más interesante- precisa del planteamiento de una taxonomía clara que, en este caso, se va a presentar según el modo en que se narró el episodio de la batalla de Roncesvalles en el capítulo dedicado a Alfonso II. ${ }^{2}$

' Son múltiples los estudios de recensio que existen hoy. El más actualizado es el de Nogales Rincón 20I6, cuya nomenclatura se utiliza aquí, y que sigue de cerca a Ruiz García 1999. Por su parte, Rodríguez Gómez 1996, es el primero, y hasta la fecha el único, que se ha detenido a analizar las relaciones entre los testimonios glosados latinos y castellanos. Ténganse, asimismo, en cuenta Espinosa Fernández 1989, Morrás 1991, Palacios Martín 1995, y Rodríguez López 2020.

${ }^{2}$ Se excluyen de esta clasificación las ediciones impresas de Granada, I545; Fráncfort, I579; Fráncfort, I603, ninguna de las cuales menciona al héroe castellano. También los manuscritos que 


\begin{tabular}{|c|c|c|}
\hline & Latinos & Castellanos \\
\hline Sin Bernardo del Carpio ${ }^{3}$ & $N_{2}, N_{4}, F^{*}$ & $N_{7}$ \\
\hline Con Bernardo del Carpio ${ }^{4}$ & $A, N_{I}, N_{3}^{*}, H$ & $N_{S}, N_{6}, E_{2}, R_{I}, P^{*}$ \\
\hline
\end{tabular}

El elemento característico de los manuscritos latinos y castellanos que transmiten el relato de Roncesvalles con la inclusión de Bernardo del Carpio es que están glosados. Rodríguez Gómez [1996, III] ya puso en relación los cuatro testimonios latinos y les otorgó cierta preeminencia con respecto a las glosas de los manuscritos castellanos. Afirmaba este autor - y es la opinión que se sigue en este trabajoque Juan de Villafuerte habría compuesto su traducción de la Anacephaleosis a partir de un manuscrito latino glosado; por ende, las adiciones castellanas tendrían su base en las latinas. No obstante, no es pertinente detenerse en este punto.

La esencia del relato es la siguiente: el rey de los francos, Carlomagno, junto a Roldán y los Doce Pares, tiene la intención de entrar en España. Sin embargo, el rey Alfonso II el Casto sale al paso de los franceses en Roncesvalles y les inflige un duro castigo. A continuación se presentan los pasajes latinos y las traducciones castellanas:

transmiten la llamada "versión sumaria», esto es, $E_{T}, N_{8}, N_{g}$; y, de igual manera, $R_{2}$ y BNE ms. 2803 , este último de reciente descubrimiento y pendiente de un estudio pormenorizado. Estos dos representan una particularidad dentro de los testimonios castellanos por contener exclusivamente las adiciones de Juan de Villafuerte de manera parcial, es decir, no incluyen texto de la autoría de Cartagena per se.

${ }^{3}$ No se dispone de digitalización del manuscrito $F$, por lo que se remite a la descripción codicológica que realiza Espinosa Fernández 1989, 198-202, y a su edición posterior en la misma obra, de la que se puede extraer su posición dentro de la taxonomía.

${ }^{4}$ El testimonio $N_{3}$ supone una particularidad dentro de la traducción manuscrita glosada. Si bien el texto principal permite adscribirlo a la facción «bernardista», las adiciones que constan se corresponden con una sección del total. Con respecto al testimonio $P$, se ha de mencionar que es un manuscrito que no contiene adiciones, aunque transmita la traducción castellana de Juan de Villafuerte.

5 Se ha optado por denominar al autor de las adiciones latinas de la Anacephaleosis como «el glosador». Si bien la tradición textual de la obra ha conservado el nombre de Juan de Villafuerte como traductor de la obra y autor de las glosas castellanas, no se tiene constancia de la identidad de ese glosador latino. Rodríguez Gómez 1996, XVII-XVIII, teorizó acerca de la existencia de una escuela historiográfica en torno al obispo de Burgos entre los que se distinguirían figuras como Diego Rodríguez de Almela o Rodrigo Sánchez de Arévalo. Por otra parte, es poco razonable pensar que fuese el propio Juan de Villafuerte el autor de las glosas latinas. Él mismo excusa su escaso dominio del arte de la traducción en el epílogo de la Anacephaleosis (uid. $N_{6}$, I75r). Además, como se verá más adelante, en el cotejo entre adiciones latinas y castellanas se advierte una amplificatio del contenido en estas últimas, algo poco probable si se tratase del mismo autor. 
Hic dicitur devicisse Carolum Magnum, regem francorum \& Rolandum \& alios famosissimos milites vocatos pares in Nauarra apud Rocesualles, ubi Carolo ad Hispaniam veniente, obuiam occurrerat. $\left[N_{4}, 22 \mathrm{r}\right]$

Hic dicitur deuicisse Carolum Magnum, regem francorum, regis Pipini filium, ac Rolandum, ac allios famosissimos milites vocatos pares in Navarra aput Rocidam Vallem. Ubi Carolo ad Yspaniam venienti obviam obcurrerat cum consobrino suo Bernardo de Carpio. ${ }^{6}\left[N_{T}, 2 \mathrm{Ov}\right]$

Refieren que el rey D. Alonso alcanzó una insigne victoria de Carlo Magno, del valiente Roldán y de los Doze Pares de Francia en el valle del Rozío, que llamamos Roncesvalles, donde cortó el paso al orgullo del Francés, que con un poderoso esército se acercaba a las fronteras de España. [ $N$, sIv; Espinosa Fernández 1989, II94]

Este dizen algunos en batalla vencer a Carlomagno, rey de Francia, hijo del rey Pepino, e a Roldán, e a otros famosos cavalleros llamados Doze Pares en Navarra, cabe Ronçasvalles. Veniendo Carlos a Espańa le salió este noble rey al camino con asaz cavallería e con su sobrino Bernaldo del Carpio. ${ }^{7}\left[N_{6}, 65 \mathrm{v}\right]$

Es interesante comprobar cómo ninguna de las dos versiones toma el relato rolandiano como referencia. El protagonista, por el contrario, es el rey de Asturias, lo que mantiene la coherencia interna de la obra. Existe la posibilidad de que en el apartado de concurrentice Cartagena hubiera expuesto los hechos como parte de las hazañas del emperador Carlomagno. ${ }^{8}$ Sin embargo, los pormenores son escasos: ni siquiera se halla una justificación para la incursión franca.

Se puede observar cómo la narración es similar salvo por dos elementos: la mención del rey Pipino y la inclusión de Bernardo del Carpio como héroe junto

${ }^{6}$ La cursiva es mía.

${ }^{7}$ Los pasajes de la traducción castellana y glosas de Juan de Villafuerte (uid. supra los estudios de recensio) forman parte de la edición crítica que estoy preparando como proyecto de tesis doctoral, cuyo título es "La Genealogía de los Reyes de España" de Alfonso de Cartagena. Estudio y edición crítica de la traducción castellana y glosas de Juan de Villafuerte, dirigida por el profesor Juan Miguel Valero Moreno. En pro de facilitar el acceso a los pasajes en la consulta de los manuscritos, he optado por limitar las referencias intratextuales a un testimonio, BNE ms. 8I5, al que se aludirá con la nomenclatura anteriormente mencionada $N_{\sigma}$ (URL: http://bdh.bne.es/bnesearch/ detalle/bdhoooooI26I4\#)

${ }^{8}$ El apartado de concurrentice es uno de los elementos característicos de la Anacephaleosis. El obispo presenta cuatro genealogías de manera paralela a los reyes de Espańa: los pontífices, los emperadores romanos, los reyes de Francia y los obispos de Burgos -línea sucesoria que culmina en el propio Cartagena-. Él mismo explica su función en el prólogo a la obra (uid. $\left.N_{6}, 3 \mathrm{v}-4 \mathrm{r}\right)$. 
a Alfonso II en la batalla. Se aprecia de manera clara la distribución de las dos versiones del relato, cada una de las cuales tiene su eco en las respectivas traducciones.

A priori, la explicación más sencilla de esta variación reside en el cotejo de las fuentes. Espinosa Fernández expone de manera pormenorizada cómo Alfonso de Cartagena se nutrió de la Historia de rebus Hispania para la composición de la Anacephaleosis [1989, 67-135]. ' De hecho, hace hincapié en una «utilización plena de la fuente» en buena parte de esta última. No obstante, en este punto concreto, se encuentran una versión que se aleja de la fuente, y una que se mantiene fiel a la misma - la «bernardista»-. ${ }^{\text {IO }}$

No obstante, incluso entre esta narración y la exposición de los hechos según Jiménez de Rada existen algunas diferencias que el glosador de la Anacephaleosis pone de manifiesto. No se limita a este cotejo con su fuente principal, sino que profundiza en estas divergencias, y ańade a la investigación el modo en que se aproximan a la batalla de Roncesvalles la Historia Turpini y el Chronicon Mundi del arzobispo Lucas de Tuy (ca. II9O - ca. I250).

Antes de detenerse en el desarrollo de la exposición de las distintas narraciones en las glosas de la Anacephaleosis se ha de ver cuál es el relato que ha transmitido cada una de las obras historiográficas aquí referidas para posteriormente abordar el análisis que de ellos se hace.

\section{LA BATALLA DE RONCESVALLES A TRAVÉS DE LAS CRÓNICAS}

La Historia Karoli Magni \& Rotholandi o Historia Turpini fue tradicionalmente atribuida al propio arzobispo Turpín, que formaba parte de la hueste de Carlomagno como uno de los Doce Pares, y de cuyo nombre se intituló posteriormente. ${ }^{12}$ Los estudios de Gaston Paris [1865] apuntan a que la obra fue compuesta

9 Hasta la fecha es el estudio más completo que se ha hecho acerca de las fuentes utilizadas por Alfonso de Cartagena en la composición de la obra. También Rodríguez Gómez 1996, XII-XIV para las fuentes de las glosas latinas y castellanas.

Io De rebus Hispanie, lib. IIII, cap. X. Se sigue la edición facsimilar de 1968.

II Se toman, para la Historia Turpini, la edición de Herbers \& Noya 200I, y para el Chronicon Mundi, la edición de Falque 2003.

${ }^{12}$ En la tradición rolandiana, Turpín tiene un papel destacado como arzobispo-guerrero y participa de la batalla a un nivel similar al de Roldán u Oliveros. Existe una diferencia fundamental con respecto de la Historia Turpini, que es su muerte en la contienda, recogida, por ejemplo, en las estrofas I65 y I66 de la Chanson (se sigue la edición de Martín de Riquer 2003), de las que se extrae el 
por un monje compostelano y otro vienense. No obstante, Bédier [I9II, II-23] desecha la teoría de un doble autor tras advertir poca consistencia en las tesis de Paris, y es seguido por Meredith-Jones [1972, 8I], quien precisa que la crónica habría sido preparada por un clérigo franco — quizá de Aix-la-Chapelle— en un contexto de cierto entusiasmo por el culto jacobeo. ${ }^{\text {I3 }}$

En la Historia Turpini, después de una epístola prologal al deán de Aquisgrán, Leoprando, se narran las incursiones de Carlomagno en la península Ibérica motivadas por la visión que tuvo del apóstol Santiago, que le encargó la liberación del territorio de los infieles y le mostró el camino para llegar a la basílica en la que se encontraba su cuerpo, que se habría de convertir, a la postre, en lugar de peregrinación para la Cristiandad.

En su primera entrada, Carlos, rey de los francos, consiguió conquistar toda España, tras lo cual regresó a Francia. La segunda incursión se produjo por los ataques del rey africano Aigolando, a quien derrotó en dos ocasiones, después de que el infiel renunciase al prometido bautismo tras ver la hipocresía del monarca cristiano en el tratamiento que este daba a los pobres de su hueste.

Después de algunas hazañas y la institución de la sede de Santiago de Compostela, los francos decidieron emprender el regreso, momento en que se produjo la traición de Ganelón.

A partir de este punto, los acontecimientos se desarrollan en gran medida de manera similar a la gesta rolandiana: la hueste cristiana es atacada, Roldán hace sonar el olifante y muere antes de que Carlomagno consiga alcanzar la retaguardia. Por último, ejecutan al traidor y sepultan al héroe.

En los capítulos finales se describe la capilla funeraria de Carlomagno, decorada con las siete artes liberales. Asimismo, se menciona su entierro, presidido por el arzobispo.

Un detalle a tener en cuenta para relacionar la Historia Turpini con las glosas de la Anacephaleosis es la inclusión del texto contenido en el Apéndice A del

lamento «Morz est Turpin, le guerrier Charlun. | Par granz batailles e par mult bels sermons | cuntre paiens fut tuz tens campiuns.|Deus li otreit seinte beneïçun» (Riquer 2003, 232). De igual manera en el fragmento editado en el mismo volumen del Roncesvalles navarro, en el que el rey Carlos debate con la cabeza del arzobispo: «raçonóse con eylla como si fuese bivo (...)» (Ibid., 397-398).

${ }^{13}$ Fernández-Ordóńez 1997, 3, y Bautista 2003, 23I, siguen a Bédier I9II, al situar la composición del Pseudo-Turpín en una fecha cercana a II40. Meredith-Jones 1972, 74, había señalado la década de iI2o como la que más habría favorecido la escritura de la crónica. En cualquier caso, se alejan de las tempranas dataciones de Paris 1865 , que consideraba la posibilidad de una primera escritura a mediados del siglo XI. 
Codex Calixtinus [Herbers \& Noya 200I, 57-58], que es el descubrimiento del cuerpo incorrupto de Turpín por parte del papa Calixto II. ${ }^{\mathrm{I}}$

El arzobispo Jiménez de Rada presenta en la Historia de Rebus Hispanice un relato de la batalla que difiere notablemente del de la Historia Turpini. En este caso, el desencadenante de los acontecimientos no reside en una traición, sino en la falta de un heredero al trono de Asturias. Así, el rey Alfonso II prometió al rey Carlos la corona si le ayudaba en sus luchas con los árabes. No obstante, los nobles de la corte se enteraron del acuerdo y, encabezados por Bernardo del Carpio, convencieron al monarca de la indignidad de su promesa y amenazaron con expulsarle del trono.

Carlomagno, iracundo, decidió entonces invadir los territorios cristianos hispánicos, cuyos pueblos se unieron por el temor a un enemigo común del que esperaban solidaridad en la lucha contra el infiel. ${ }^{\mathrm{IS}}$ La lucha se desarrolló de manera similar al relato rolandiano, salvo que el héroe francés se hallaba en la vanguardia, igualmente desconectado de la columna en la que viajaba Carlos. De esta manera el rey Alfonso, junto a Bernardo del Carpio, que estaba al frente de un ejército de árabes, derrotaron a los francos, que emprendieron la huida.

El arzobispo Lucas de Tuy recoge un relato cercano al anterior en el Chronicon Mundi, si bien con algunos matices de notable importancia con respecto de la obra contemporánea de Jiménez de Rada.

En este caso Carlomagno ya se encontraba en la península Ibérica; don Lucas cuenta que había sometido a "Gotos et Yspanos qui erant in Catalonia et in montibus Vasconie et in Nauarra» [Chronicon Mundi 2003, 235]. El desencadenante vuelve a ser el vasallaje del reino asturiano al rey franco, en este caso, exigido por él mismo y no ofrecido por Alfonso II. Bernardo del Carpio vuelve a ser el defensor de la honra hispánica, aunque en esta crónica la imagen que parece transmitirse es la de insensatez por rebelarse contra el estandarte de la Cristiandad, Carlomagno y, además, aliarse con los sarracenos encabezados por Marsil. Es elocuente cómo se aborda la muerte de Roldán, puesto que la crónica aduce los pecados del ejército hispano como motivo:

${ }^{14}$ El glosador de la Anacephaleosis conoce un manuscrito de la Historia Turpini que contiene los apéndices que Paris (I865, 36-38) denomina supplementa, esto es, los apéndices que, según él, acompañan a la mayor parte de los testimonios de la Historia Turpini. En este sentido, el estudio de recensio más completo sigue siendo el de Meredith-Jones 1972, 5-32.

${ }^{\text {Is }}$ "[...] quanto ab illis timebant, de quorum debebant praesumere caritate, et quibus erant coniuncti fibula cristiana.» De rebus Hispanice 1968, 83. 
Marsil rex barbarorum, qui preerat Cesarauguste ciuitati, euocatis innumerabilibus milibus Sarracenorum et predicto Bernaldo atque quibusdam Nauarris secum asociatis, et cum Francis inito bello Rodlandus, Britannicus prefectus, Anselmus comes, Egiardus, mense Caroli prepositus, cum aliis multis nobilibus Francis exigentibus peccatis nostrorum occisi sunt. ${ }^{16}$ [Ibid.]

Lucas de Tuy concluye su narración describiendo cómo Carlomagno consigue vengar sus pérdidas destruyendo a los árabes — ni rastro de los cristianos_- y cómo visita la iglesia de Santiago, a la que el rey Alfonso concede honores de sede metropolitana. El detalle más curioso, quizá, es la reconciliación de Bernardo con Carlomagno hasta el punto de tomarlo bajo su protección, y a cuyo lado lucharía en defensa del imperio. ${ }^{17}$ Es un elemento narrativo quizá tomado del perdido Cantar de Bernardo del Carpio, como apuntó Entwistle [1928, 319].

Estos son, por tanto, los tres relatos de la batalla de Roncesvalles que se ha decidido exponer, con atención a sus similitudes y, sobre todo, a sus interesantes divergencias. En el interior de las glosas del capítulo de Alfonso II de la Anacephaleosis, todos ellos son referidos, analizados y cotejados, y así tratará de mostrarse en el siguiente punto de este trabajo.

\section{LA BATALLA DE RONCESVALLES EN LAS GLOSAS DE LA ANACEPHALEOSIS}

La complejidad estructural de las glosas del capítulo de Alfonso II conduce a que se deba analizar cuidadosamente la forma y función de cada elemento narrativo para concretar hasta qué punto el modus operandi observable puede responder a un plan premeditado o si se puede hablar de técnica narrativa, cuestión especialmente delicada en el caso de una doble autoría —o bien, traducción y autoría-.

Se van a analizar las glosas latinas y castellanas como una unidad, si bien las referencias al contenido corresponderán a la traducción. Salvo variantes de copista y/o traductor, el contenido es idéntico hasta una sección concreta del capítulo,

${ }^{16}$ La cursiva es mía.

${ }^{17}$ «inter Romanos et Germanos atque Gallos se [Bernardus] gloriose gessit» Chronicon Mundi 2003, 236.

${ }_{18}$ Este autor precisa que habría sido Carlomagno el que, una vez consciente del error de atacar a los cristianos, visita Santiago y San Salvador de Oviedo con el beneplácito de Alfonso II. En ese viaje encuentra a Bernardo y se lo lleva a Francia. Son elementos del cantar extraídos de la hipotética prosificación contenida en la Estoria de España. 
momento en que acaba el texto en los manuscritos latinos y solo continúa en los de Villafuerte. En la siguiente tabla se observa esta distribución del contenido:

\begin{tabular}{|l|c|c|}
\hline \multicolumn{1}{|c|}{ Pasaje de las glosas } & Glosas latinas & Glosas castellanas \\
\hline Hechos de la Historia Turpini & $A, N_{I}, N_{3}, H$ & $N_{S}, N_{\sigma}, E_{2}, R_{I}$ \\
\hline El ídolo Salamcadis de Vandalia & Sí Fínal de glosas en $N_{3}$ & Sí \\
\hline $\begin{array}{l}\text { Primera contraposición de las cua- } \\
\text { tro opiniones. La causa de la venida } \\
\text { de Carlomagno }\end{array}$ & Sí & Sí \\
\hline $\begin{array}{l}\text { Elementos de la Historia de Rebus } \\
\text { Hispaniae y el Chronicon Mundi }\end{array}$ & Sí & Sí \\
\hline $\begin{array}{l}\text { Segunda contraposición y acuerdo } \\
\text { de las opiniones }\end{array}$ & Sí & Sí \\
\hline Referencia a las Decretales & Final de las glosas & Sí \\
\hline $\begin{array}{l}\text { Razonamiento de por qué Carlo- } \\
\text { magno no ganó las ciudades que se } \\
\text { le atribuyen }\end{array}$ & $* * *$ & Sí \\
\hline $\begin{array}{l}\text { Razonamiento de por qué Carlo- } \\
\text { magno no abrió el Camino de San- } \\
\text { tiago }\end{array}$ & $* * *$ & Sí \\
\hline Elementos de las Enfances & $* * *$ & Sí \\
\hline Resto de glosas acerca de Alfonso II & $* * *$ & \\
\hline
\end{tabular}

Con el objetivo de unificar la lengua de los fragmentos citados, se ha optado por mostrar el texto castellano puesto que, como se observa en la tabla, es el único que contiene la totalidad del contenido, si se tiene en cuenta la amplificatio que se a anteriormente [uid. supra].

Para comenzar la exposición del capítulo, Villafuerte muestra la premisa:

Léese d'este rey don Alonso el casto, llamado segundo (sic), vencer a Carlomagno rey de Francia, emperador de los romanos, hijo del rey Pepino que fue de Lombardía, e de Theutonia, e de Francia. E a Roldán, con otros famosos caballeros veniendo a Espańa, en Navarra, cave Ronçasvalles. $\left[N_{6}, 65 \mathrm{v}\right]$

La base del relato es el texto de Cartagena. De ahí se toman detalles como que el vencimiento se produce en la venida del rey franco, y no en el regreso, como se 
defiende en otra versión. Además, las opiniones de los otros historiadores que se desarrollarán en las adiciones se plantearán con la premisa anterior como punto de partida.

A continuación, el relato comienza con la exposición pormenorizada de la primera de las «opiniones» que, en este caso, corresponde a las «ystorias de los francos» y especialmente, matiza, la que el arzobispo Turpino dedicó al deán Leopando $(s i c)$. Por si esta precisión dejase alguna duda de qué texto tiene presente el autor de las glosas, el modo en que se adhiere a la narración de la Historia Turpini despeja cualquier incógnita.

En primer lugar, se explica el motivo por el que los franceses entraron en Espańa — recuérdese el encargo del apóstol Santiago a Carlomagno-, tras lo que se van sucediendo los episodios incluidos en la crónica franca tal y como aparecen en esta: la primera conquista de toda la Península; el regreso para enfrentarse al rey Aigolando; las batallas contra el gigante y el rey de Sevilla, etc.

Finalmente, se alude a los acontecimientos de Roncesvalles desde la óptica del Pseudo-Turpín, además de caracterizarse por un tratamiento pormenorizado. Se menciona que la tragedia del ejército se produjo por la traición de Ganelón en connivencia con Marsil, rey de Zaragoza y se detalla la muerte de Roldán. En dos elementos se aprecia su apego a la Historia Turpini, por oposición a la versión más puramente rolandiana: el descubrimiento de la batalla por el milagro de Turpín, que ve el alma de Roldán siendo llevada al cielo; y la no participación del propio arzobispo en la batalla.

Como se ha mencionado antes, lo último que refiere el glosador es el episodio del descubrimiento del cuerpo incorrupto del arzobispo, contenido en los apéndices a la obra. ${ }^{19}$

A continuación, se retorna a la premisa central y se efectúa la primera contraposición de opiniones. El glosador menciona que el relato de Cartagena se opone a lo que acaba de narrar. Es más, «non dixo cosa d'este nuestro rey don Alonso ni de Bernaldo de Carpio» $\left[N_{6}, 66 r\right]$, algo que habría de sorprender, puesto que la postura de don Alfonso es que todos estos acontecimientos tuvieron lugar bajo el gobierno del rey casto.

19 Puede ser de cierta relevancia a la hora de delimitar a qué familia de manuscritos pertenecía aquel que tuvo presente el glosador de la Anacephaleosis. Paris I865, 36, apunta que la mayor parte de los códices conservados transmiten los mencionados apéndices. No obstante, no se hace referencia en la Anacephaleosis a ninguno de los otros textos incluidos en ellos, como el relato de un milagro de Roldán. 
Entonces, incorpora otras versiones del relato, la del arzobispo Jiménez de Rada, que defiende la derrota de los franceses a manos de Alfonso II y Bernardo del Carpio; y la de Lucas de Tuy, que a esto ańade la ayuda del rey Marsil a los hispanos. No obstante, no es la única disensión a la que alude el glosador. Inmediatamente después resalta que «en la cabsa de su venida parecen todos tres [Cartagena, Rada y Tuy] discordar [respecto de Turpín]» [Ibid.]. De esta manera, la opinión de la crónica franca se enfrenta a los relatos de los arzobispos hispánicos que se expusieron en el apartado anterior.

Se observa en estos puntos cómo se organiza narratológicamente la proliferación de fuentes cronísticas. El glosador enumera las posturas con dos puntos de partida: la premisa de Alfonso de Cartagena y el relato de la Historia Turpini en este caso como referencia comparativa con respecto a las otras obras de las que se sirve para ampliar la información contenida en la Anacephaleosis.

Sin embargo, a la hora de tratar con estas fuentes de autoridad, el glosador se muestra meticuloso para no desprestigiar ninguna de ellas. Se acepta que sus posturas no solo difieran sino que se contradigan, pero enfatiza que los tres — Rada, Tuy y Turpín - son arzobispos y por tanto, «fieles cristianos e verdaderos relatores» $[$ Ibid.]. En este punto el glosador excusa dichas confrontaciones aduciendo que es comprensible que cada uno hable en favor de su nación. No obstante, no se limita a ello, sino que afirma lo siguiente: «Aunque de mi flaco juyzio enmienda del mejor entender parece poder sus dichos en alguna manera acordar» [Ibid.], esto es, se han de intentar conjugar las distintas narraciones debido a que todas ellas son obra de fuentes de autoridad eclesiástica, por lo que es inconcebible que transmitan un relato falso de manera consciente.

Las glosas latinas concluyen con un proyecto de conjugación de las versiones propuestas. Puede entenderse que en primer lugar el emperador recobró toda España de los moros, tras cuyo fallecimiento habría vuelto a perderse. Entonces, habría comenzado la recuperación de territorios, llevada a cabo, en este caso, por los reyes de España hasta el momento de la escritura de las adiciones. ${ }^{20}$

De esta manera se integrarían todos los relatos en uno sin llegar a desprestigiar alguna de las fuentes. Más bien al contrario, puesto que el glosador mantiene su

${ }^{20}$ Juan de Villafuerte establece como fecha de finalización de escritura de las glosas castellanas el 2I de noviembre de I463, por lo que, si se sigue la opinión de Rodríguez Gómez (I996, VII) para relacionar su trabajo con las glosas latinas, la composición de estas hubo de tener lugar entre 1456 y 1463 . 
cautela recurriendo a una autoridad como las Decretales, mediante las que legitima el método de conciliación de las posturas. ${ }^{21}$

A partir de este punto se puede afirmar con cierta seguridad que el glosador es Juan de Villafuerte, dado que no se conserva un manuscrito latino que transmita más información. Por su parte, los textos castellanos continúan el relato y se puede apreciar un leve cambio de registro.

Villafuerte adopta un tono incisivo que muestra en su adhesión directa al relato de Jiménez de Rada. Enumera pormenorizadamente las ciudades de España que fueron recuperadas por los reyes cristianos peninsulares — se incluye a reyes de Portugal y Aragón - durante doscientos años con el objetivo de desechar la idea de que fuesen conquistadas por Carlomagno $\left[N_{6}, 66 \mathrm{v}-67 \mathrm{r}\right.$; De rebus Hispania $1968,84-85]$.

Además, refuta otra de las bases de la Historia Turpini: la apertura del camino de Santiago. Véase la cercanía de la narración de Rada y Villafuerte:

(...) nec stratam Sancti Iacobi suo itinere potuit publicare, cui non obvenit transitum vallis Roscidæ penetrare. [De rebus Hispania 1968, 85]

Aun me tengo por dicho que non abrió el camino de Santiago, porque al tiempo que vino a la batalla con el rey Alfonso el casto non pudo pasar el puerto de Roçasvalles, pues que antes que a él legase fue vencido. Pues si el puerto non pasó, ¿̨ómo pudo abrir el camino largo para Santiago? $\left[N_{6}, 67 \mathrm{r}\right]$

Lo único que separa estos fragmentos es una cierta tendencia dramática por parte de Villafuerte, apreciable en otros puntos de las glosas. Como recapitulación, concluye con «E ansí parece razonable que ni el emperador ganó cosa alguna en España ni tampoco abrió el camino francés para Santiago.» [Ibid.].

No obstante, su último acercamiento a la cuestión tiene un cariz conciliador, siempre fiel al relato de Jiménez de Rada, pues concede que en realidad Carlomagno sí pudo lograr alguna hazaña en España, pero hubo de ser mientras se encontraba bajo la protección del rey Galafrén en Toledo, introduciendo así una alusión a la leyenda del Mainete o Les enfances de Charlemagne.

${ }^{21}$ La referencia que da es «E parece en el capítulo cum tu de testibus» $\left(N_{\sigma}, 66 \mathrm{v}\right)$, esto es, Decretales. Lib. II. Tit. XX De testibus. Capitulum XVI «Cum tu...». En este, se aboga por la conciliación de testimonios a priori contradictorios mediante la presunción de que ambos pueden haber sucedido en momentos distintos.

${ }^{22}$ Bautista 2003, 223-247, sintetiza gran parte de la información que se posee acerca del Mainet o Les Enfances de Charlemagne, cantar épico cuyos fragmentos conservados datan de la segunda mi- 
A partir de este punto, Villafuerte vuelve a ocuparse del rey Alfonso II. Más adelante se refiere de nuevo a la figura de Carlomagno, esta vez de manera pormenorizada, trazando un perfil físico e incluyendo una alabanza de sus virtudes. ${ }^{23}$ Sorprende especialmente que recupere la cuestión rolandiana, si bien brevemente, para señalar que «Roldán con los otros pares e cavalleros vencieron a los moros en España, aunque por la traición del conde Galalón fueron muertos, segund es dicho" $[N, 68 \mathrm{r}]$.

Esta inclusión es, en efecto, notable por la desconexión que se aprecia con respecto del tratamiento tan orgánico conferido a la cuestión anteriormente y, por otra parte, porque contradice el postulado que a priori parecía defender Juan de Villafuerte, alineado con el arzobispo Jiménez de Rada. La posibilidad más razonable es la adhesión de este al relato de Lucas de Tuy, fuente recurrente en las glosas castellanas, aunque obvia algunos elementos clave que son mencionados antes. No obstante, no es pertinente detenerse en este aspecto.

\section{CONCLUSIONES}

Mediante el análisis de la batalla de Roncesvalles en el capítulo de Alfonso II en la Anacephaleosis y, con atención específica al tratamiento que se le otorga en las extensas glosas latinas y castellanas, se ha pretendido reflexionar acerca de las técnicas narrativas que se aprecian en la composición de un relato cuyo objetivo es conjugar la información contenida en cuatro obras historiográficas compuestas por fuentes de autoridad con, además, el valor ańadido de su vinculación eclesiástica. No obstante, existe una cierta disensión entre el que se identifica como glosador latino y Juan de Villafuerte, quizá menos meticuloso este último en su tarea, o alejado de la marcada conciencia conciliadora apreciable en la primera parte del texto.

De esta manera, se observa que el objetivo del glosador latino es la presentación de un relato unificado mediante la yuxtaposición de las distintas versiones

tad del siglo XII. Este ha permanecido mediante prosificaciones en la Estoria de España y otras obras historiográficas. Tiene un valor especial la investigación de Bautista para esta disertación debido a los nexos que presenta entre la Historia Turpini y De rebus Hispania. El autor apunta a que el arzobispo Jiménez de Rada habría utilizado esta alusión hipotéticamente para desechar los planteamientos de la crónica franca, lo que conduce directamente a este trabajo, con la continuación de la misión del Toledano por parte de Juan de Villafuerte.

${ }^{23}$ Es característico de las glosas castellanas tengan una estructura paralela al capítulo de la Anacephaleosis. Después de algunos apuntes acerca del monarca en cuestión es frecuente que se amplíe la información correspondiente a los personajes contenidos en las concurrentic. 
que toma como fuentes de autoridad. Su base es siempre el texto de Cartagena, que pretende amplificar. Sin embargo, se encuentra con el escollo de haber de conjugar opiniones que difieren y llegan a ser contradictorias. La solución propuesta, tras haber expuesto cada uno de los relatos, es la conciliación conseguida a través de la teoría del «doblamiento del fecho» $\left[N_{6}, 66 r\right]$, que sustenta en las Decretales. De esta manera, legitima todas las versiones y conserva intacta, en consecuencia, la autoridad del obispo Cartagena, así como la del resto de historiadores eclesiásticos.

\section{BIBLIOGRAFÍA}

Bautista, Francisco, «La tradición épica de las Enfances de Carlomagno y el Cantar de Mainete perdido", Revista de Filología Española, LXXXIII, $3^{\circ}-4^{\circ}$ (2003), págs. 223-247. DOI: <https://doi.org/I0.3989/rfe.2003.v83.i3/4.I30>.

Bédier, Joseph, La "Chronique de Turpin» et le pèlerinage de Compostelle, Toulouse: Imprimerie et Librairie Édouard Privat, I9II.

Cabanes Pecourt, Ma Desamparados (ed.), Rodrigo Jiménez de Rada, Opera, Valencia: Anubar, Textos Medievales, 22, 1968 (reimpresión facsímil de la edición de I793).

Cacho Blecua, Juan Manuel, «De la Chronica Turpini a la Historia del Emperador Carlomagno y los Doze Pares de Francia» en Elvira Fidalgo Francisco (coord.), Formas narrativas breves en la Edad Media: actas del IV Congreso, Santiago de Compostela, 8-1o de julio de 2004, Santiago de Compostela: Universidade de Santiago de Compostela, 2005, págs. I8I-208.

Castets, Ferdinand (ed.), Historia Karoli Magni \& Rotholandi, Montpellier: Bureau des Publications de la Société des Langues Romanes; París: Maisonneuve et $\mathrm{C}^{\mathrm{ie}}$, 1880 .

Corpus Iuris Canonici, Graz: Akademische Druck- u. Verlagsanstalt, I959 (Electronic reproduction. Vol. I-2. New York, NY: Columbia University Libraries: 2007). URL: <http://www.columbia.edu/cu/lweb/digital/collections/cul/ texts/ldpd_6029936_002/index.html>.

Entwistle, William J., "The "cantar de gesta" of Bernardo del Carpio», The Modern Language Review, XXIII, no 3 \& 4 (1928), págs. 307-322. DOI: <https:// doi.org/Io.2307/3714460>.

Espinosa Fernández, Yolanda (ed.), La Anacephaleosis de Alonso de Cartagena: edición, traducción, estudio, Madrid: Editorial de la Universidad Complutense, I989 (Colección Tesis Doctorales, nº 243/89), 3 vols. 
Falque, Emma (ed.), Lucas de Tuy, Chronicon Mundi, Turnhout: Brepols, 2003. Fernández-Ordóńez, Inés, «El tema épico-legendario de Carlos Mainete y la transformación de la historiografía medieval hispánica entre los siglos XIII y XIV", en Jean-Philippe Genet, dir., L'histoire et les nouveaux publics dans l'Europe médiévale (XIII-XV siècle): Actes du colloque international organisé par la Fondation Européene de la Science à la Casa de Vélasquez, Madrid, 23-24 avril 1993, París: Éditions de la Sorbonne, I997, págs. 89-II2. URL: <http://www.uam.es/FyL/ documento/I446774236212/I997_El_tema_epico-legendario_de_Carlos.pdf>.

Fernández Valverde, Juan (ed.), Rodrigo Jiménez de Rada, Historia de los hechos de España, Madrid: Alianza Editorial, 1989.

Herbers, Klaus, \& Manuel Santos Noya (eds.), Liber Sancti Jacobi "Codex Calixtinus» Libro IV, Santiago de Compostela: Xunta de Galicia, $200 I$.

Herbers, Klaus (coord.), El Pseudo-Turpin. Lazo entre el Culto Jacobeo y el Culto de Carlomagno. Actas del VI Congreso Internacional de Estudios Jacobeos, Santiago de Compostela: Xunta de Galicia, 2003.

Horrent, Jules, La "Chanson de Roland" dans les littératures françaises et espagnole au Moyen Age, Paris: Les Belles Lettres, 1951.

Lambert, Élie, "L'Historia Rotholandi» du Pseudo-Turpin et le pelèrinage de Compostelle», Romania, 69 (1946), págs. 362-387. URL: <https://www.persee. fr/doc/roma_0035-8029_1946_num_69_275_3619>.

Langford, Walter M., «Bernardo del Carpio», Hispania, 20, 3 (1937), págs. 253264. URL: <https://www.jstor.org/stable/332002>.

Meredith-Jones, Cyril (ed.), Historia Karoli Magni et Rotholandi ou Chronique du Pseudo-Turpin, Ginebra: Slatkine Reprints, 1972.

Morrás, María, «Repertorio de obras, mss. y documentos de Alfonso de Cartagena (ca. 1384-I456)», Boletín Bibliográfico de la Asociación Hispánica de Literatura Medieval, 5 (I99I), págs. 213-248. URL: <https://www.academia.edu/67883I/_Repertorio_de_obras_mss._y_documentos_de_Alfonso_de_Cartagena_ca._I384-I456>.

Nogales Rincón, David, "La Genealogía de los Reyes de España de Alonso de Cartagena: linaje e imagen regia en la Castilla del Cuatrocientos», Revista de poética medieval, 30 (2016), págs. 233-257. URL: <https://recyt.fecyt.es/index. $\mathrm{php/revpm/article/viewFile/49382/pdf \_ 2>.}$

Oswald, Katherine P., «Representations of Alfonso II and Alfonso III in the Legend of Bernardo del Carpio", Lemir, I9 (2015), págs. I03-II6. URL: <https:// parnaseo.uv.es/Lemir/Revista/Revistarg/o3_Oswald_Katherine.pdf>.

Palacios Martín, Bonifacio (ed.), Anacephaleosis. El "Libro de la genealogía de los Reyes de España» de Alfonso de Cartagena, Valencia - Madrid: Scriptorium Biblioteca Nacional de España, I995. 
Paris, Gaston, De Pseudo-Turpino, París: Franck, 1865.

Puyol, Julio (ed.), Lucas de Tuy, Crónica de España, Madrid: Tip. de la «Rev. de Archivos, Bibliotecas y Museos», 1926.

Riquer, Alejandra de (ed.), Eginhardo, Vida de Carlomagno, Madrid: Alianza Editorial, 20I9.

Riquer, Martín de (ed.), Chanson de Roland. Cantar de Roldán y el Roncesvalles navarro, Barcelona: Acantilado, 2003.

Rodríguez Gómez, José Luis, Las glosas de Juan de Villafuerte a la Anacephaleosis de Alfonso de Cartagena: estudio de las fuentes y edición parcial, Madrid: UNED, 1996. [Memoria de Licenciatura, inédita]

Rodríguez López, Pablo (ed.), Alfonso de Cartagena, Genealogía de los Reyes de España. Versión sumaria, Salamanca: SEMYR-Biblioteca Cartagena, 2020. URL: $<$ https://bibliotecacartagena.net/monografia/genealogia-de-los-reyes-deespana-version-sumaria>.

Rodríguez Montederramo, José Luis, «Las glosas latinas a la Anacephaleosis y las adiciones de Juan de Villafuerte», Reales Sitios: Revista del Patrimonio Nacional, I29 (1996), págs. 16-25.

Rubio García, Luis, «Historia y poesía. Bernardo del Carpio», Estudios Románicos, I2 (2000), págs. 7-30. URL: <http://revistas.um.es/estudiosromanicos/ article/view/7920I>.

Ruiz García, Elisa, «El sueño de la edición múltiple: unos testimonios tempranos», Pliegos de Bibliofilia, 8 (1999), págs. 5-26.

—_, "Avatares codicológicos de la Genealogía de los Reyes de España», Historia. Instituciones. Documentos, 27 (2000), págs. 295-33I. URL: <https://dialnet. unirioja.es/servlet/articulo?codigo $=58369>$ 